
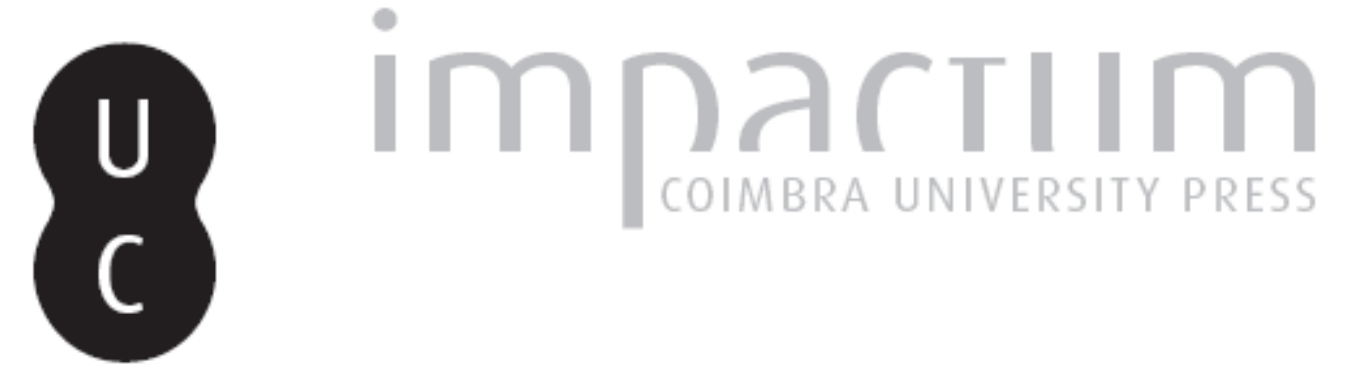

\title{
Terra Sigillata marmoreada proveniente de Tróia de Setúbal
}

Autor(es): $\quad$ Sousa, Élvio Melim de

Publicado por: Imprensa da Universidade de Coimbra

URL persistente:

URl:http://hdl.handle.net/10316.2/45448

DOI:

DOI:https://dx.doi.org/10.14195/1647-8657_35_9

Accessed : $\quad$ 26-Apr-2023 15:12:47

A navegação consulta e descarregamento dos títulos inseridos nas Bibliotecas Digitais UC Digitalis, UC Pombalina e UC Impactum, pressupõem a aceitação plena e sem reservas dos Termos e Condições de Uso destas Bibliotecas Digitais, disponíveis em https://digitalis.uc.pt/pt-pt/termos.

Conforme exposto nos referidos Termos e Condições de Uso, o descarregamento de títulos de acesso restrito requer uma licença válida de autorização devendo o utilizador aceder ao(s) documento(s) a partir de um endereço de IP da instituição detentora da supramencionada licença.

Ao utilizador é apenas permitido o descarregamento para uso pessoal, pelo que o emprego do(s) título(s) descarregado(s) para outro fim, designadamente comercial, carece de autorização do respetivo autor ou editor da obra.

Na medida em que todas as obras da UC Digitalis se encontram protegidas pelo Código do Direito de Autor e Direitos Conexos e demais legislação aplicável, toda a cópia, parcial ou total, deste documento, nos casos em que é legalmente admitida, deverá conter ou fazer-se acompanhar por este aviso.

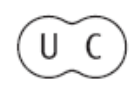


UNIVERSIDADE DE COIMBRA

FACULDADE DE LETRAS

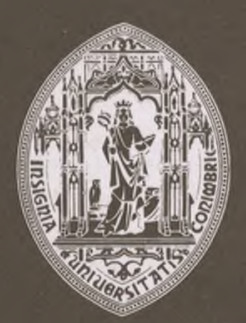

\section{CONIMBRIGA}

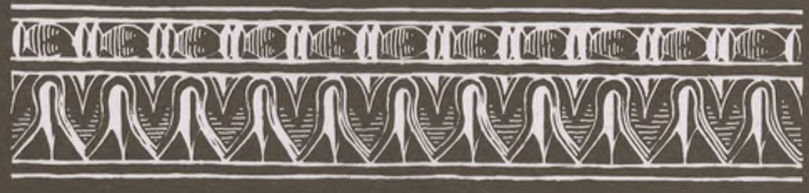

VOLUME XXXV - 1996 
ÉLvio Melim DE Sousa

Conservador dos Museus da Câmara Municipal de Sintra

\section{TERRA SIGILLATA MARMOREADA PROVENIENTE}

DE TRÓIA DE SETÚBAL

"Conimbriga" XXXV (1996) p. 207-215

RESUMO: Estudam-se seis fragmentos de terra sigillata marmoreada prove-

nientes de recolhas de superfície efectuadas em Tróia de Setúbal.

Este fabrico, pouco comum e pouco duradouro dentro da produção de sigillata sudgálica de $\mathrm{La}$ Graufesenque, possui características próprias únicas, ocorrendo na Hispânia em quantidades relativamente frequentes, dentro da sua manifesta raridade.

Três das peças ostentam marcas de oleiros conhecidos dentro do reportório de La Graufesenque: Lepidus, Iucundus e Anii ou Emii.

SUMMARY: In this article the author publishes 6 fragments of marbled terra sigillata, all surface finds from the site of Tróia near Setúbal.

Marbled terra sigillata is both relatively rare and short lived amongst the production of $\mathrm{La}$ Graufesenque in South Gaul. Taking this rarity into account it can be said to occur slightly more frequently amongst Spanish sigillata.

The ware shows certain unique characteristics.

Three of the fragments presented here carry potters stamps already known from La Graufesenque: Lepidus, Iucundus and Anii or Emii.

Conimbriga, 35 (1996) 207-215 
(Página deixada propositadamente em branco) 


\section{"TERRA SIGILLATA" MARMOREADA PROVENIENTE DE TRÓIA DE SETÚBAL *}

Data de cerca do último quartel do século I a. C. o início da manufactura da "Terra Sigillata" denominada de "Sud-Gálica", essencialmente em locais de forte tradição oleira.

Baseados, de princípio, nos fabricos aretinos (toma-se, por vezes, difícil distingui-los), a "Terra Sigillata" Sud-Gálica (TSSG) conheceu, todavia, numerosas formas novas e grandes modificações a nível da pasta, adquirindo os seus produtos um tom de vermelho mais carregado e um brilho mais intenso.

Foi sobretudo a nível da gramática decorativa, contudo, que se verificaram as maiores diferenças em relação aos fabricos de "sigillata" itálica, saldando-se essas alterações por uma grande originalidade nos motivos usados - abandona-se as figuras humanas moldadas, tão caras às produções anteriores, e surge a técnica da decoração em zonas demarcadas. Obtinham campos decorativos através de linhas horizontais e, mais tarde, através de linhas horizontais e verticais, os quais recebiam uma decoração profusa e contínua, no primeiro caso, essencialmente à base de folhas e caules de plantas, "óvulos alongados" e "duplas línguas" e, no segundo, à base de "métopas" e de "ponías de flecha".

Conhecem-se, pelo menos, quatorze centros de fabrico de TSSG no Sul da GáliaO), sendo os mais importantes os grupos de Montans, La Graufesenque e Banassac, a eles pertencendo a grande maioria dos

* Algumas letras das marcas dos oleiros possuem pontos por baixo de si próprias (reconstituições).

(') Bram, Narbonne, Montans, Valéry, Aspiran, Carrade, Rozier, Banassac, La Graufesenque, Rajol, Roc, Jonquieres, Crambade e Brive, segundo A. VERnHET, 1986, p. 33. 
fomos e dos oleiros de TSSG conhecidos. É atribuída ainda a estes três centros a parte mais significativa da produção de "Sigillata" Sud-Gálica, cobrindo um período cronológico balizado entre 10 a. C. e 260 d. C.

Embora se denotem grandes afinidades entre os fabricos dos vários centros oleiros de TSSG, apenas La Graufesenque parece ter produzido e exportado um tipo exclusivo designado comummente por "Sigillata Marmoreada". Este tipo, caracterizado por possuir um "glanztonfilm" claro e amarelado com laivos vermelhos irregulares que imitam os veios do mármore, os de algumas pedras semi-preciosas ou, então, os vidros "millefiori" (2), ocorre na Hispânia em quantidades relativamente frequentes, dentro da sua manifesta raridade, confirmando, assim, uma grande procura por parte dos compradores desta região.

Não se sabe ao certo, no entanto, qual a sua origem, havendo autores que aventam a hipótese de se tratar de acidentes de fabrico dentro das cozeduras de cerâmica normal de TSSG, baseando-se, para isso, na ausência de formas ou pastas peculiares em relação aos demais produtos gálicos, opinião que refutamos inteiramente. Até porque, e tendo apenas em consideração a amostragem de Tróia de Setúbal que ora se apresenta, observamos três técnicas diferentes de utilização do "glanztonfilm" claro e amarelado: com laivos avermelhados imitando o mármore sobre as faces externa e interna das peças (fragmentos $\mathrm{n} .^{\circ} 1$, 3 e 4); somente na interna (fragmentos n. ${ }^{\circ} 5$ e 6); e sem laivos, quer na face externa, quer na interna (fragmento $n .^{\circ} 2$ ). Tal leva-nos a crer estarmos na presença de uma técnica de efeito decorativo intencional e não perante meros acidentes. Recorde-se, igualmente, que o marmoreado quando é aplicado, é-o homogeneamente sobre as superfícies das peças, tanto lisas como decoradas, denotando-se um cuidado por vezes extremo na sua apresentação final.

Outras duas razões que nos levam ainda a afirmar ser esta técnica (marmoreado) propositada são o facto de apenas surgir nos produtos fabricados em La Graufesenque $\left(^{3}\right)$, pois que se de acidente se tratasse, ocorreria, como é óbvio, em todos os demais fabricos de TSSG, o que não acontece e o facto do tipo marmoreado apenas cobrir um pequeno

$\left.{ }^{2}\right)$ O efeito "marmoreado" era conseguido através do uso de duas coberturas mal ligadas e detentoras de cores e composições diferentes, as quais eram aplicadas indiscriminadamente sobre vasos lisos ou decorados.

$\left(^{3}\right) \quad \mathrm{Na}$ bibliografia consultada não é feita qualquer referência a peças marmoreadas fora dos fabricos de La Graufesenque. 
período cronológico dentro daquele centro, somente entre os finais do Reinado de Tibério/princípios do de Cláudio e cerca de $70 \mathrm{~d}$. C., e não a totalidade da produção de La Graufesenque, como seria normal e lógico.

A colecção que ora apresentamos é composta por seis únicos fragmentos provenientes de recolhas de superficie efectuadas em Tróia de Setúbal, mais concretamente - e valendo-nos de mapa inserto em publicação recente sobre esta estação - entre o 'conjunto 8 ' e os 'conjuntos 9 e 10' (Ponta do Verde) de oficinas de salga (cfr. F. May et, et alii, 1994, pp. 98 e 99, fig. 49), os quais nos foram amavelmente cedidos para estudo pelo Dr. Eurico Sepúlveda, a quem agradecemos $\left({ }^{4}\right)$.

Apenas um fragmento apresenta decoração barbotinada (n. ${ }^{\circ}$ ), sendo possível detectar com precisão a forma de quatro dos seis fragmentos em estudo.

Os fragmentos n. ${ }^{\circ} 2, \quad 3$ e 4 (fundos) ostentam marcas [L]EPID(us).L(Fecit), IVCVND(us).F(ecit) e [A]N1L(1) ou [EJMILtf) - respectivamente, todas elas de oleiros do centro de La Graufesenque e com paralelos conhecidos.

Em relação aos fragmentos n. ${ }^{\circ} 5$ e 6 , adiantamos a hipótese de pertencerem à mesma peça, razão pela qual surgem agrupados na estampa.

\section{CATÁlOGO:}

N. ${ }^{\circ} 1$ - fragmento de bordo e parede de taça.

Forma: Drag. 36.

Diâmetro: 144 mm (a nível do extremo exterior da aba).

Pasta: vermelha-acastanhada, de tom vivo, dura, porosa, de grão médio, de fractura irregular e cortante, sonora.

Engobe: externo/castanho-amarelado claro, espesso, pouco brilhante, com laivos vermelhos irregulares imitando o mármore; interno/idêntico ao externo.

${ }^{4}$ Temos conhecimento da existência de outras peças de "Sigillata Marmoreada" exumadas nas escavações de Tróia de Setúbal, as quais se encontram incorporadas nas colecções do Museu Nacional de Arqueologia.

* Agradecemos a ajuda da Dra. Françoise Mayet e do Dr. J. Cardim Ribeiro na leitura das marcas de oleiro apresentadas neste estudo.

** Os desenhos insertos neste artigo devem-se ao Dr. Eurico Sepúlveda, a quem agradecemos.

Conimbriga, 35 (1996) 207-215 
Decoração: apresenta sobre a parte superior da aba um motivo vegetai estilizado (folha?), em relevo e obtido pela técnica de barbotina.

Cronologia: entre 60 e 70 d. C.

N. ${ }^{\circ} 2$ - fragmento de fundo de taça.

Forma: Ritt. 8.

Diâmetro: $63 \mathrm{~mm}$ (a nível do extremo exterior do pé em anel).

Pasta: vermelha-acastanhada clara, dura, pouco porosa, de grão fino, de fractura irregular e cortante, sonora.

Engobe: externo/castanho-amarelado claro, espesso, brilhante. Possui apenas uma pequena faixa avermelhada na parede, a qual corre a toda a volta da peça, junto ao arranque do pé em anel; interno/idêntico ao externo.

Cronologia: entre 40 e 70 d. C.

Marca: [L]EPID(us).L(Fecit) — a marca patente nesta peça encontra-se fragmentada, sendo impossível ler-se a primeira letra do conjunto. Mesmo assim, são bem legíveis as letras (...)EPID.L, que interpretamos, no seu todo, como a abreviatura do nome do oleiro Lepidus, de La Graufesenque. Para o " $L$ " inscrito depois do ponto, adiantamos a hipótese de se tratar de uma má impressão do punção de $F$ para Fecit, sendo esta a hipótese que se nos afigura mais plausível. Ainda assim, poderemos igualmente estar, talvez, perante uma impressão não completamente gravada, perante uma letra invertidamente impressa, perante uma marca incompleta (onde falta uma ou mais letras), ou, por outro lado, na presença de uma marca resultante de uma matriz defeituosa. Na bibliografia consultada detectou-se apenas dois paralelos para este " $L$ " ( $F$ mal gravado) sobre peças de TSSG (GABLER, D. e KELLNER, H.-J., 1993) - VICTORINVS L, interpretada como VICTORINVS $F$ (ecit), [Taf. 24, n. 4 e p. 242] e SEVERVS LEC, interpretada como SEVERVS FEC (it) [Taf. n. ${ }^{\circ}$ 26, n. $^{\circ} 2$ e p. 243]. Confrontar, todavia, no geral, a marca F. LEPID. (com $E$ em retro) patente na peça $\mathrm{n} .{ }^{\circ} 286$ de "Sigillata Sud-Gálica" exumada em Conímbriga (A. AlARCÃO, 1975, p. 118). Confrontar, também, F. LAUBENHEIMER e L. Albagnac, 1986, p. 118, n. 9; C. BÉmONT e A. Bourgeois, 1986, p. 282; M. Beltrán Lloris, 1990, p. 93 e Dias Diogo, 1980, n. ${ }^{\circ} 119$.

N. ${ }^{\circ} 3$ - fragmento de fundo com pé em anel de taça.

Forma: Drag. 24/25 ou, talvez, Drag. 27 (devido às características do pé em anel, fomos obrigados a alargar o espectro de formas para este fragmento).

Diâmetro: 54 mm (a nível do extremo exterior do pé em anel).

Pasta: vermelha-acastanhada, de tom vivo, dura, pouco porosa, de grão médio, de fractura irregular e cortante, sonora.

Engobe: externo/castanho-amarelado claro, espesso, brilhante, com laivos vermelhos irregulares imitando o mármore. $\mathrm{Na}$ área interior externa definida pelo pé em anel e pelo fundo da taça, não se observam laivos marmoreados; interno/idêntico ao externo.

Conímbriga, 35 (1996) 207-215 
Cronologia: entre 40 e $70 \mathrm{~d}$. C.

Marca: IVCVND(us).F(ecit) — damos como paralelos para esta marca de oleiro, entre outras, as variantes dos fragmentos de "terra sigillata" sudgálica de Conímbriga publicados por A. ALARCÃO e patentes no volume IV das Fouilles de Conimbriga, 1975, sob os n. $^{\circ} 273$ (IVCVN[DI]), $21 A$ (IVCV[ND1] 275 («OFIVCV.), p. 116 e n..$^{\circ} 276$ (iOFTV[...] p. 117, Pis. XXV, XXX e XXXI, as marcas OFIVCVN e $1 V C V N$, da Citânia de Briteiros (J. M. BAIRRÃo Oleiro, 1951, p. 94), a marca 1 VCVNDVS, de Torre de Palma (S. da VeIGA Ferreira, 1969, p. 169) e sobretudo as duas marcas referenciadas por P. PAUNIER (1986, p. 268, fig. 3), IVCVNF e IVCVNDV F, onde aquele autor cita A. LÄUfER (1980), referentes a produções de oleiros de La Péniche. Confrontar ainda DiAS DiOGO, 1980, n. ${ }^{\circ} 97$ a 103; C. BÉMONT e A. BOURGEOIS, 1986, p. 282; M. BeLtrán Lloris, 1978, p. 101; ib., 1990, p. 93 e A. Bourgeols, 1991, p. 153, Quadro 55 (4), n. 73 a 80 e p. 154, Quadro 55 (5), n. ${ }^{\circ} 81$.

$\mathrm{N} .^{\circ} 4$ - pequena taça fragmentada.

Forma: Ritt. 8.

Diâmetro: $65 \mathrm{~mm}$ (a nível do extremo exterior do bordo).

Pasta: vermelha-acastanhada, de tom vivo, dura, pouco porosa, de grão fino, de fractura irregular e cortante, sonora.

Engobe: externo/castanho-amarelado claro, espesso, brilhante, com laivos vermelhos irregulares imitando o mármore; interno/idêntico ao externo.

Cronologia: entre 40 e $70 \mathrm{~d}$. C.

Marca: [A]NIL ou [E]MII. - esta marca é quase ilegível, pois para além de ter sido mal impressa, apresenta-se muito desgastada, tomando-se, desse modo, impossível lê-la com rigor. Todavia, parece-nos ser de arriscar a hipótese de se tratar da marca [A]NIL ou [E]MII., abreviatura dos oleiros de La Graufesenque Annius e Ernia. Para a primeira hipótese temos um paralelo em Conímbriga, fragmento $\mathrm{n}^{\circ} 237$ de "terra sigillata" sudgálica, se bem que se duvide aqui da leitura da marca em questão e se lance a hipótese de se estar perante parte da marca do oleiro Canti, em detrimento da de Annius. Sob o número n. ${ }^{\circ}$ 238, também de Conímbriga, pode ler-se num fragmento sud-gálico a marca $A N N I O$, que damos aqui como variante paralela, apesar de não se conhecer para este caso concreto quaisquer outras marcas idênticas (Cfr. A. AlARCÃO, 1975, p. 110, n. ${ }^{\circ} 237$ e 238 e Pis. XXX e XXXI). Temos igualmente conhecimento de marcas de oleiro com o nome de ANNIVS na Citânia de Briteiros e em Vipasca (S. VeIgA Ferreira, 1969, p. 166). Confrontar também C. BÉmont e A. Bourgeois, 1986, p. 279; M. Beltrán Lloris, 1978, p. 100 e ib., 1990, p. 92. Para a segunda hipótese, damos como paralelos prováveis as marcas em retro IIME e IIM[ ], usadas, ao que se pensa, pelo oleiro Ernia e patentes sobre peças marmoreadas exumadas em Belo e referenciadas por A. BOURGEOIS, 1991, sob os n. ${ }^{\text {os }} 55$ e 56 do Quadro n. 55 (3), p. 152. 
N. ${ }^{\circ} 5$ - fragmento de bordo e parede carenada (?) de taça.

Forma: indeterminada. Confrontar, todavia, os perfis das formas ditas "raras ou inéditas" de Montans apresentadas por T. MARTIN (1986, p. 62, fig. 4, n. ${ }^{\circ} 15$ e 16 e p. 63, fig 5, n. ${ }^{\circ} 18$ ) e ainda a forma Drag. 33 (Fouilles de Conimbriga, 1975, IV, PI. XXII, n. ${ }^{\circ} 126$ e 127).

Pasta: vermelha-acastanhada, de tom vivo e algo escuro, dura, porosa, de grão fino, de fractura regular, sonora.

Engobe: externo/castanho-amarelado claro, espesso, brilhante. Possui ainda uma faixa avermelhada e irregular na parede, de cerca de lem de largura média, implantado na zona logo acima da carena; interno/idêntico ao externo, mas com laivos vermelhos irregulares imitando o mármore.

Cronologia: entre 40 e 70 d. C.

N. ${ }^{\circ} 6$ - fragmento de parede carenada (?) de taça.

Forma: indeterminada (cfr. fragmento anterior).

Pasta: idêntica à do fragmento $n .^{\circ} 5$.

Engobe: externo e intemo/idênticos, respectivamente, aos do fragmento anterior.

Cronologia: entre 40 e 70 d. C.

\section{BIBLIOGRAFIA}

AlarCãO, A., 1975, “ Les Sigillées Sud-Galliques”, Fouilles de Conimbriga, t. IV, pp. 68-149.

Bairrão Oleiro, J. M., 1951, "Elementos para o estudo da «Terra Sigillata» em Portugal. I — Marcas de oleiro encontradas no País", Revista de Guimarães, LXI, pp. 81-111.

Beltrán Lloris, M., 1978, Cerâmica Romana. Tipología y Clasificación, pp. 91-108. 1990, Guia de la Cerámica Romana, pp. 89-110.

BÉmont, C., 1974, "Le Décor des Vases Sigillés", Les Dossiers de T Archeologie, n. ${ }^{\circ}$, Set.-Out., pp. 67-76.

Bémont, C. e Bourgeois, A., 1986, "Les Noms de Potiers. Ateliers situées en France", Documents dArcheologie Française (= DAF), n. ${ }^{\circ}$ 6, pp. 278-286.

Bourgeols, A., 1991, Fouilles de Belo, VI, "Les Sigillées", Chap. II, «Les Sigillées Gallo-Romaines», Collection de la Casa de Velázquez, n. ${ }^{\circ} 34$, pp. 79-194.

Dias Diogo, A. M., 1980, "Marcas de «Terra Sigillata» Sud-Gálica em Portugal", GEC A, Lisboa.

Duran-Lefebvre, M., 1954, "Étude sur la Décoration des Vases de Montans", Galia, XII, pp. 73-88.

GABler, D. e Kellner, H.-J., 1993, "Die Bildstempel von Westerndorf II", Bayerische Vorgeschichtsblätter, 58, pp. 242, 243 e Tafs. 24 e 26.

Hermet, F., 1934, La Graufesenque (Condatomago), Paris.

Conimbriga, 35 (1996) 207-215 
Laubenheimer, F. e AlbagnaC, L., 1986, “Jonquières et Saint-Satumin”, $D A F, \mathrm{n} .{ }^{\circ}$, pp. 117-120.

LÄUfER, A., 1980, “ La Péniche - Un atelier de céramique à Lousonna”, Cahiers $d$ ' Archéologie Romande, n. ${ }^{\circ}$ 20, Lousonna 4, Lausanne.

MAIA, Maria A. G. P., 1971, Contribuição para o estudo da "Terra Sigillata" de Tróia de Setúbal, Dissertação de Licenciatura em História, F.L.L., pp. 8-14.

MARTIN, T., 1986, “Montans”, $D A F$, n. ${ }^{\circ}$ 6, pp. 58-71.

MAYET, F., 1978, "Les Importations de Sigillées a Mérida au 1er Siècle de Notre Ère", Conimbriga, XVII, pp. 79-100.

MAYET, F., et allL, 1994, Un grand complexe industriel à Tróia (Portugal), pp. 98 e 99 e fig. 49.

Oswald, F. e Pryce, T. D., 1920, An Introduction to Study of Terra Sigillata, Cap. IX, pp. 218-222 e PI. XXVIII.

PAunier, P., 1986, "La Production de Terre Sigillée en Suisse au 1er S. de notre Ère", $D A F$, n. ${ }^{\circ}$ 6, pp. 265-268.

VEIGA FERREIRA, S., 1969, "Marcas de oleiro em território português", O Arqueólogo Português, Série III, voi III, pp. 131-177.

VERNHET, A., 1976, "Création flavienne de six services de vaisselle a La Graufesenque”, Figlina, 1, pp. 13-27.

1986, "Centre de Production de Millau. Atelier de La Graufesenque”, $D A F$, n. ${ }^{\circ} 6$, pp. 96-103.

1986, "Les Ateliers du Sud de la France. Présentation Générale", $D A F$, n. ${ }^{\circ}$ 6, pp. 33 e 34.

Conimbriga, 35 (1996) 207-215 
EST. I

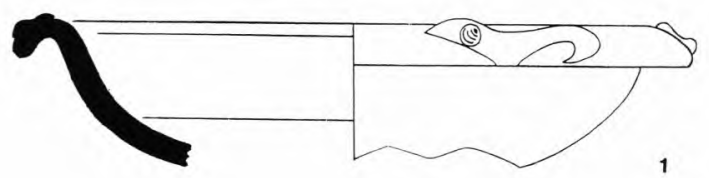

(anen
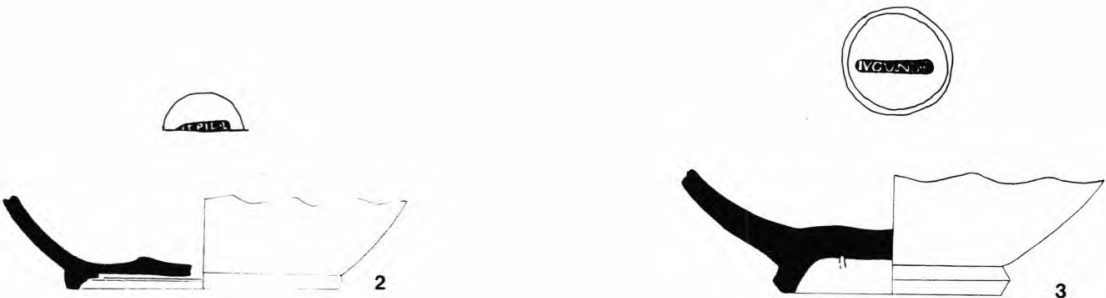

mis

(
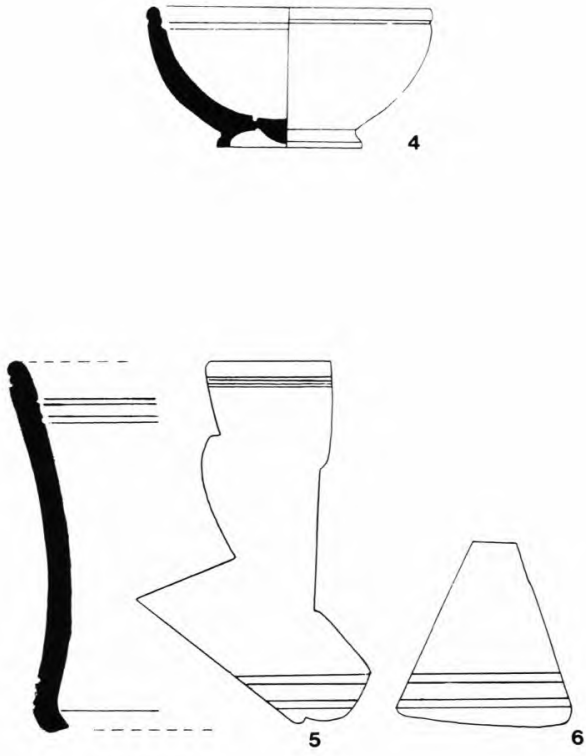

o

$-7-n^{3}$ 